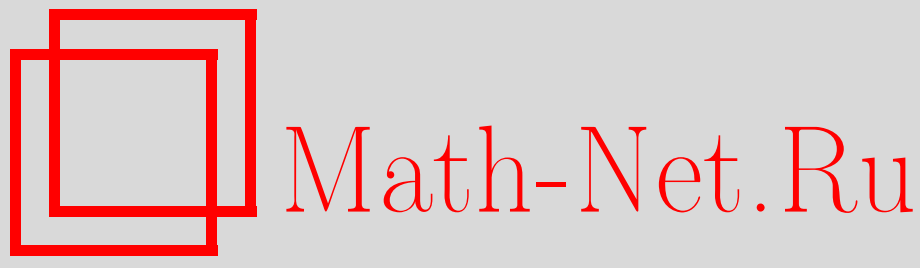

Обпероссийский математический портал

В. Х. Хаханян, Функциональная алгебраическая модель, эквивалентная штрих-реализуемости Клини, Матем. заметки, 2004, том 75, выпуск 1, 155-156

DOI: https://doi.org/10.4213/mzm541 
Использование Общероссийского математического портала Math-Net.Ru подразумевает, что вы прочитали и согласны с пользовательским соглашением http://www. mathnet.ru/rus/agreement

Параметры загрузки:

IP: 35.173 .219 .149

26 апреля 2023 г., 15:37:34

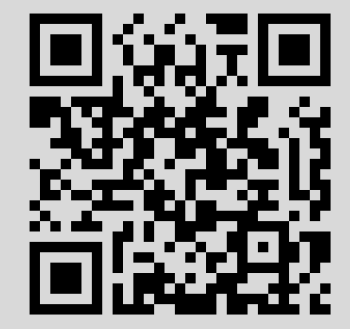




\section{ФУНКЦИОНАЛЬНАЯ АЛГЕБРАИЧЕСКАЯ МОДЕЛЬ, ЭКВИВАЛЕНТНАЯ ШТРИХ-РЕАЛИЗУЕМОСТИ КЛИНИ}

\section{В. Х. Хаханян}

В одной из своих работ А. Г. Драгалин предложил очень общий подход к построению моделей в стиле равномерных алгебр для нестандартных логик и, в частности, для интуиционистской логики (см. [1]). Изложение (достаточно ясное, но без очевидных деталей) сопровождается рядом примеров для арифметики (также см. [1]). В последнем из примеров рассматривается штрих-реализуемость Клини (см. [2, столбец С]), и автор приводит “. . . модель, соответствующую штрих-реализуемости Клини ... " [1, с. 194]. Однако связь между приводимой моделью и штрих-реализуемостью Клини такова: “. . $\|\varphi\|=T \Leftrightarrow((\mid \varphi) \wedge \mathrm{HA} \vdash \varphi)$ ”; (см. также [1, с. 195]; сравни с [3]). Конечно, с помощью приведенной модели (соответствующей именно формульной реализуемости из [3]) можно доказать свойства дизъюнктивности и экзистенциальности для арифметики (именно этот результат и стремится получить автор, используя подходящую равномерную алгебру). Однако штрих-реализуемость Клини не совпадает с выводимостью в интуиционистской арифметике НА.

Как отмечалось выше, в [1] дается ряд примеров, в которых для той или иной модели НА (в том числе и для моделей реализуемостного типа) приводится соответствующая этой модели функциональная псевдобулева алгебра (ФПБА). Точная формулировка ФПБА дана в [1] и здесь мы отметим кратко только факты, необходимые для дальнейшего. Если F - множество форм ФПБА, то для любых $\mathrm{f}$ и $\mathrm{g}$ из $\mathrm{F}$ ( $\mathrm{f}$ и $\mathrm{g}$ - формы с одним и тем же количеством аргументных мест) существуют формы из F: f $\wedge \mathrm{g}, \mathrm{f} \vee \mathrm{g}, \mathrm{f} \supset \mathrm{g}$ с тем же набором аргументных мест. Затем определяется функциональная алгебраическая модель (ФАМ) для логико-математического языка и для заданной $А$ оМ опреде-

(C) В. Х. ХАханян 
ляется значение в ней для всякой формулы нашего языка. Главное отличие от обычных алгебраических моделей в том, что значением $\|\varphi\|$ формулы $\varphi$ будет некоторая форма $f_{\varphi}$ из ФПБА. Теперь можно фиксировать язык арифметики, объектную область и функцию $\widehat{C n s t}$. После этого каждая модель определяется заданием набора: В (псевдобулева алгебра), F и Pr-оценка предикатов.

Пусть заданная ФПБА - модель для штрих-реализуемости Клини, т.е. имеется такое отображение формул языка арифметики в множество форм, что для всякой формулы $\varphi$ : она |-реализуема тогда и только тогда, когда $f_{\varphi} \in 1$ (единица алгебры В). Рассмотрим два различных, неразрешимых в НА, утверждения $\varphi$ и $\psi$ (т.е. НА $\forall \forall$, НА $\forall \psi$, НA $\forall \neg \varphi$, НА $\forall \neg \neg \psi$ ). Так как в НА не выводятся $\varphi$ и $\psi$, то формулы $\neg \varphi$ и $\neg \psi$ являются невыводимыми, |-реализуемыми формулами языка арифметики. Если в $\Phi A M$ им соответствуют формы $\mathrm{F}_{\neg \varphi}$ и $\mathrm{F}_{\neg \psi}$ соответственно, то эти формы принадлежат 1 алгебры, а тогда форма $\mathrm{F}_{\neg \varphi} \vee \mathrm{F}_{\neg \psi}=\mathrm{F}_{\neg \varphi \vee \neg \psi}$ (соответствующая в $\Phi$ АМ формуле $\neg \varphi \vee \neg \psi$, см. [1, с. 187]), также принадлежит 1 нашей алгебры и, следовательно, формула $\neg \varphi \vee \neg \psi$ является |-реализуемой. Но это влечет, что НА $\vdash \varphi$ или НА $\vdash \psi$, что невозможно в силу выбора $\varphi$ и $\psi$. Таким образом, доказана

ТЕОРема. Не существует ФПБА, соответствующей|-реализуемости Клини.

\section{СПИСОК ЦИТИРОВАННОЙ ЛИТЕРАТУРЫ}

1. Драгалин А. Г. Функциональные алгебраические модели // Семиотика и информатика. Т. ХІІІ. М.: ВИНИТИ, 1979. С. 184-195. 2. Kleene S. С. // Lecture Notes in Math. 1973. V. 337. P. 96. 3. Драгалин А. Г. Математический интуиционизм. Введение в теорию доказательств. М.: Наука, 1979.

Московский государственный университет путей сообщения (МИИТ) 